\title{
Rhetorical Move Analysis in Humanities and Hard Science Students' Undergraduate Thesis Abstracts
}

\author{
Dian Pratiwi, Budi Hermawan*, Rd. Dian Muniroh \\ English Education Department, Universitas Pendidikan Indonesia \\ *Corresponding author.Email: budihermawan@upi.edu
}

\begin{abstract}
Abstract is an important part of an undergraduate thesis that contains a summary of the entire data. A good abstract must be patterned well using a rhetorical move. This study aims to identify the rhetorical move used in abstracts by Humanities and Hard Science students in Universitas Pendidikan Indonesia. 30 abstracts in Bahasa Indonesia and their translation in English (a total of 60 abstracts) were taken from six disciplines i.e., English Language Education, Indonesian Language and Literature Education, Sundanese Language Education, International Program on Science Education, Chemistry Education, and Mathematics Education. Content Analysis was used as the instrument of analysing data. Hyland's Five-Move Analysis model was also used as the guideline for the analysis. The result showed that Findings and Methodology were mostly used in the undergraduate thesis abstract. In conclusion, different disciplines affect the implementation of the rhetorical move in abstracts. The finding is important to describe the rhetorical move used by Humanities and Hard Science students in making abstracts. However, this study only reveals the rhetorical move used by six disciplines. Because of that, it is recommended for future researchers to analyse rhetorical move used by other disciplines; not only in making thesis abstracts but also dissertations abstracts.
\end{abstract}

Keywords: Hard Science, Humanities, rhetorical move, undergraduate thesis abstract

\section{INTRODUCTION}

Writing in academic way is something that people often do in the field of academics relevant with their disciplines. Academic Writing, in general, refers to a broad type of writing set in academic context (Turmudi, 2017). According to Hogue (2008), academic writing is the kind of writing which is done in college classes to explain something or to give information about something to particular audience. There are different types of academic writing, such as journal, undergraduate thesis, thesis, dissertation, and so forth.

Undergraduate thesis is one of the requirements that must be fulfilled when someone is about to finish his or her studies at the higher educational level. According to $\mathrm{Wu}$ (2019), graduation thesis is the last teaching link before graduation which is of great significance to the cultivation of students' professional ability and learning ability. Rising (2014) stated that thesis refers to a master's level "final" paper for their research that earns them the Master's. It is a research document in a formal form which discusses particular topic regarding the learner's interest in his or her field of study. A thesis is composed by several parts, which are introduction, literature review, research method or methodology, findings and discussion, and conclusion. The format of the undergraduate thesis is similar, consisting of five chapters which are, Introduction, Review of the Literature, Materials and Methods, Experimental Chapters, and General Discussion or Conclusions (Chandrasekhar, 2001). There are additional parts which play important role to the thesis, abstract and reference.

Abstract is one of the most important parts of a research paper or thesis. It is the initial part of a thesis which contains a summary of the entire data. According to Bhatia (1993), abstract is a description or factual summary of the much longer report and is meant to give the reader an exact and concise knowledge of the full article. It contains information about; (1) What the author did, (2) How the author did it, (3) What the author found, and (4) What the author concluded. In terms of the communicative purpose(s), the abstract presents a faithful and accurate summary, which is representative of the whole article. McCombes (2019) explained that abstract usually contains of 150-300 words to report the aims and outcomes of the research so that readers know exactly what the paper is about. After the title, the 
abstract is generally the readers' first encounter with a text and is often the point at which they decide whether to continue reading and give the accompanying article further attention, or to ignore it.

Bhatia (1993) has identified four types of rhetorical move in abstracts. Those are (1) Introducing Purpose, (2) Describing Methodology, (3) Summarizing Results, and (4) Presenting Conclusions. Then, the theory from Bhatia (1993) has been enriched by several experts including Hyland (2000). According to Hyland (2000), the five moves which appear in abstracts are (1) Introduction which establishes context of the paper and motivates the research or discussion, (2) Purpose which indicates purpose, thesis or hypothesis, and outlines the intention behind the paper, (3) Methodology which provides information on design, procedures, assumptions, approach, data, etc., (4) Product which states the main findings or results, the argument, or what was accomplished, and (5) Conclusion which interprets or extends results beyond scope of paper, draws inferences, points to applications or wider implications. This theory has been used to analyse rhetorical move in RAAs in the fields of linguistics, economics, mechanical engineering, and other fields of study. Saboori and Hashemi (2013) analysed the rhetorical move used by three disciplines: linguistics, economics, and mechanical engineering. It was found that Introduction was the least frequent move used in the abstract. Then, Amnuai (2019) analysed the rhetorical moves of English Research Article Abstracts (RAAs) written by authors from different cultural and linguistic backgrounds. The results showed that Introduction, Purpose, Method, and Product were the conventional moves in the international corpus. Meanwhile in the Thai corpus, purpose, method, and product were the conventional move. Kurniawan et al. (2019) analysed abstracts from four AL journals with different quartile. The analysis revealed that journal quartile does not necessarily affect the manifestation of all moves and steps. The number of occurrences of Step 1-describing participants and Step 3-describing procedure in the Method move was similar in all journals. Then, the Purpose and Findings were obligatory in all journals. Another research was conducted by Tamela (2020) which analysed move structure of RAAs in two journals: TEFLIN and TESOL Quarterly. The result showed that the move patterns mostly used are Introduction, Purpose, Method, and Product (I-P-M-Pr). On the other hand, Li (2020) analysed the rhetorical move used in Chinese RAAs and its English translation. The results showed that Product and Method were mostly used in English RAAs.

Studies analysing the rhetorical move in students' thesis abstract are not as many. The topic has been underresearched. Since abstract is the most important part of a thesis that is used by students to fill the requirements for their graduation, we have to pay attention to the move and step in writing an abstract in order for the abstract to represent the entire content of our thesis which and entice readers to read it further. Therefore, this study aimed to analyse the rhetorical move used in students' thesis abstract of undergraduate students from different disciplines. Hyland's (2000) Five-Move Analysis model was used as the framework of this study.

\section{METHOD}

This section contains the explanation on how the study is conducted.

\subsection{Research Design}

A descriptive-qualitative was used as a design of this study. According to Litosseliti (2020), qualitative research is concerned with structures and patterns, and how something is. In this study, the researcher identified the moves and steps used in making the undergraduate thesis abstracts by the Humanities and Hard Science students in Universitas Pendidikan Indonesia.

\subsection{Data Sources}

The data were collected from several undergraduate theses of the Humanities and the Hard Science's education major that were published in Repository UPI's website. 30 abstracts written in Bahasa Indonesia and their translation in English (with a total of 60 abstracts) were taken from six different disciplines i.e., English Language Education, Indonesian Language and Literature Education, Sundanese Language Education, International Program on Science Education, Chemistry Education, and Mathematics Education.

\subsection{Data Collection}

This study used a random sampling technique by choosing the data that were published in Repository UPI from 2016 to 2020. First, the researcher went to the Repository UPI's website. Here, the researcher filtered the data based on students' majors and their graduation year. After that, the data were chosen randomly. Then, the abstracts were analysed by using Hyland's (2000) theory. Finally, the abstracts were compared.

\subsection{Data Analysis}

The data were analysed by using the Hyland's (2000) theory (see Table 1). According to Hyland's (2000), Move 1 establishes context of the paper and motivates the research or discussion, Move 2 indicates purpose, thesis or hypothesis, Move 3 establishes design, procedures, approach, data, Move 4 states findings, and Move 5 interprets the results, draws inferences, points to wider implications. 
Table 1. A Classification of Rhetorical Move in Abstracts

\begin{tabular}{lcl}
\hline \multicolumn{1}{c}{ Move } & Step & \multicolumn{1}{c}{ Description } \\
\hline $\begin{array}{l}\text { Introduction } \\
\text { (I) }\end{array}$ & 1 & $\begin{array}{l}\text { Arguing for topic significance } \\
\text { Making topic generalization } \\
\text { Defining the key term(s) }\end{array}$ \\
Purpose (P) & 4 & $\begin{array}{l}\text { Identifying gap } \\
\text { Stating general and/or specific } \\
\text { purpose of the research } \\
\text { including the hypothesis } \\
\text { Describing participants/data } \\
\text { sources } \\
\text { Describing instrument(s) } \\
\text { Describing procedure } \\
\text { context and } \\
\text { Describing the main specific } \\
\text { findings of the research }\end{array}$ \\
Product (Pr) & 1 & 2 \\
Conclusion & 1 & $\begin{array}{l}\text { Deducing conclusion } \\
\text { Evaluating the significance of } \\
\text { the research } \\
\text { Stating limitation } \\
\text { Presenting recommendation or } \\
\text { implication }\end{array}$ \\
\hline
\end{tabular}

In analysing the data, researcher first identified the moves and steps that were used in students' undergraduate thesis abstract. After that, the researchers identified the differences between rhetorical moves used in the abstracts. Then, the results were presented by writing it on findings and discussion.

\section{FINDINGS AND DISCUSSION}

This section reveals the findings of the study and the discussion on the findings. The study elaborates the findings and the discussion in a simultaneous discussion. According to the analysis, the result showed that the five rhetorical moves and its steps were used by Humanities and Hard Science's students of Universitas Pendidikan Indonesia in making the abstracts both written in Bahasa Indonesia and in English. However, there were not all of the moves and steps existed in each abstract.

Table 2. Move Realization in Indonesian Abstracts across Disciplines

\begin{tabular}{ccc}
\hline \multirow{2}{*}{ Move } & \multicolumn{2}{c}{ Move Occurrence Percentage } \\
\cline { 2 - 3 } & Humanities & Hard Science \\
\hline Move 1 & $71 \%$ & $29 \%$ \\
Move 2 & $50 \%$ & $50 \%$ \\
Move 3 & $50 \%$ & $50 \%$ \\
Move 4 & $56 \%$ & $44 \%$ \\
Move 5 & $58 \%$ & $42 \%$ \\
\hline
\end{tabular}

\subsection{Move Used in the Humanities and Hard Science Students' Undergraduate Thesis Abstracts}

All of the moves according to Hyland's (2000) FiveMove Analysis Model were used by the Humanities and the Hard Science students in making their undergraduate thesis abstracts. Both Table 2 and Table 3 explained the occurrence of those five moves in cross-department students' abstracts which were written in Bahasa Indonesia and in English.

The analysis showed that both the Bahasa Indonesia and English abstracts had the same percentage of move occurrence. It happened because the students translated the abstract using literal translation technique so that the components of the translated abstracts, such as the verbs, subjects, and other language elements did not differ from the original abstract (which was not translated). Because of that, the rhetorical moves used by the students in the Bahasa Indonesia and English abstracts were the same. As the result, the percentage of the move occurrence was also the same.

In this study, Move 1 - Introduction was the most used move by Humanities students which is $71 \%$, followed by Move 5 - Conclusion and Move 4 - Product with the percentage of each is $58 \%$ and $56 \%$. This result was the same with previous studies conducted by Amnuai (2019) and Tamela (2020) which found that Move 1 Introduction was mostly used in making the abstract. Meanwhile, the least moves used were Move 2 - Purpose and Move 3 - Methodology with the same percentage which is $50 \%$. On the other hand, for the Hard Science abstracts, Move 2 - Purpose and Move 3 - Methodology were the most frequent move used with a total of $50 \%$. Then, Move 4 - Product followed by Move 5 Conclusion was the second and the third frequent move used with the percentage of each is $44 \%$ and $42 \%$. In line with the previous study conducted by Saboori and Hashemi (2013) which found that Introduction was the least frequent move used in the abstract, in this study, Move 1 - Introduction was also the least move used by the Hard Science students with a total of $29 \%$.

Table 3. Move Realization in English Abstracts across Disciplines

\begin{tabular}{ccc}
\hline \multirow{2}{*}{ Move } & \multicolumn{2}{c}{ Move Occurrence Percentage } \\
\cline { 2 - 3 } & Humanities & Hard Science \\
\hline Move 1 & $71 \%$ & $29 \%$ \\
Move 2 & $50 \%$ & $50 \%$ \\
Move 3 & $50 \%$ & $50 \%$ \\
Move 4 & $56 \%$ & $44 \%$ \\
Move 5 & $58 \%$ & $42 \%$ \\
\hline
\end{tabular}


Table 4. Step Realization in Indonesian Abstracts across Disciplines

\begin{tabular}{cccc}
\hline \multirow{2}{*}{$\begin{array}{c}\text { Move } \\
(\mathrm{M})\end{array}$} & $\begin{array}{c}\text { Step } \\
\text { (S) }\end{array}$ & \multicolumn{2}{c}{ Step Occurrence Percentage } \\
\cline { 3 - 4 } & & Humanities & Hard Science \\
\hline Move 1 & 1 & $69 \%$ & $31 \%$ \\
& 2 & $83 \%$ & $17 \%$ \\
& 3 & $100 \%$ & $0 \%$ \\
& 4 & $0 \%$ & $0 \%$ \\
Move 3 & 1 & $50 \%$ & $50 \%$ \\
& 2 & $44 \%$ & $56 \%$ \\
& 3 & $48 \%$ & $52 \%$ \\
Move 5 & 1 & $60 \%$ & $40 \%$ \\
& 2 & $0 \%$ & $0 \%$ \\
& 3 & $0 \%$ & $0 \%$ \\
& 4 & $67 \%$ & $33 \%$ \\
\hline
\end{tabular}

In addition, the high occurrences of Move 1 Introduction in the Humanities' abstracts showed that the students of each discipline tried to establish context of the paper and motivates the research or discussion more than others. Meanwhile, the most frequent used of Move 2 Purpose and Move 3 - Methodology by the Hard Science' abstracts explained that the students attempted to indicate purpose, thesis or hypothesis, and outlines the intention behind the paper and provide more information on design, procedures, assumptions, approach, data, etc.

\subsection{Steps of each Move Used in the Humanities and Hard Science Students' Undergraduate Thesis Abstracts}

Besides moves, steps on rhetorical moves in undergraduate thesis abstracts were also analysed in this study. Table 4 and Table 5 indicated the occurrence of the steps of each move in Humanities and Hard Science students' undergraduate thesis abstracts which were written in Bahasa Indonesia and its translation in English.

Based on the Table 4 and Table 5, the data showed that the percentage of Step used by the Humanities and Hard Science students in making the abstracts were almost the same. However, Move 2 and Move 4 were not discussed since it did not have any step.

In this study, Move 1 Step 4 - identifying gap, Move 5 Step 2 - evaluating the significance of the result, and Move 5 Step 3 - stating limitation did not occur in the Humanities and Hard Science students' thesis abstracts. The table showed that Move 1, Step 2 - making topic generalization and Step 1 - arguing for topic significance were the most Step that appeared in the abstracts. However, Move 1 Step 3 - defining the key term(s) was only used by the Humanities students in making the abstracts with a total of $100 \%$. In Move 3, Step 2 describing instrument(s) and Step 3 - describing procedure and context in the abstracts had the same percentages, which are $44 \%$ and $48 \%$ for Humanities abstracts while $56 \%$ and $52 \%$ for the Hard Science abstracts. The difference occurred in Move 3 Step 1 describing participants/data sources. In Indonesian abstracts, both the Humanities and Hard Science students had the same percentage of using Move 3 Step 1, which is $50 \%$. It was similar with the study conducted by Kurniawan et al. (2019) which found that the number of occurrences of Step 1-describing participants and Step 3describing procedure in the Method move was similar in all journals. However, in English abstracts, the Hard Science students used it the most with 54\% than the Humanities with $46 \%$. On the other hand, in Move 5, Step 4 - presenting recommendation or implication and Step 1 - deducing conclusion were mostly used by the Humanities students with $67 \%$ and $60 \%$. Meanwhile, Step 2 - evaluating the significance of the research and Step 3 - stating limitation were not used at all.

The results of the findings showed that different disciplines affect the use of Step in writing the undergraduate thesis abstracts. There were differences in the English translation skills possessed by the crossdepartment students in Universitas Pendidikan Indonesia. In Indonesian abstract, students assumed that one part referred to a certain Step. However, after the abstract was translated into English, the students assumed that it referred to another Step. Besides that, some of them thought that there was a Step that was not that important in an abstract, so they decided not to use that Step in writing the abstract. By using one kind of Step in the abstracts, it indicated that the authors tried to point out what they thought as important and to emphasize that part in order to make the audiences paid more attention to the abstracts.

Table 5. Step Realization in English Abstracts across Disciplines

\begin{tabular}{cccc}
\hline \multirow{2}{*}{$\begin{array}{c}\text { Move } \\
(\mathrm{M})\end{array}$} & $\begin{array}{c}\text { Step } \\
(\mathrm{S})\end{array}$ & \multicolumn{2}{c}{ Step Occurrence Percentage } \\
\cline { 3 - 4 } & 1 & Humanities & Hard Science \\
\hline Move 1 & 1 & $69 \%$ & $31 \%$ \\
& 2 & $83 \%$ & $17 \%$ \\
& 3 & $100 \%$ & $0 \%$ \\
& 4 & $0 \%$ & $0 \%$ \\
Move 3 & 1 & $46 \%$ & $54 \%$ \\
& 2 & $44 \%$ & $56 \%$ \\
& 3 & $48 \%$ & $52 \%$ \\
Move 5 & 1 & $60 \%$ & $40 \%$ \\
& 2 & $0 \%$ & $0 \%$ \\
& 3 & $0 \%$ & $0 \%$ \\
& 4 & $67 \%$ & $33 \%$ \\
\hline
\end{tabular}




\section{CONCLUSION}

Based on the analysis, it can be concluded that a total of 60 undergraduate thesis abstracts of the Humanities and Hard Science field of study that were taken from Repository UPI have been analysed to find out the rhetorical move used by the students in making their undergraduate thesis abstracts. The findings show that all moves were used by the Humanities and Hard Science students in making their abstracts. On the other hand, not all of the moves used in the abstracts use the steps that are owned by each move. Regarding the move, both the Bahasa Indonesia and English abstracts made by the students from different disciplines had the same percentage of move occurrence. However, this study found that Move 1 - Introduction was the most used move by Humanities students. Meanwhile, Move 2 Purpose and Move 3 - Methodology were the least move used by the students in their undergraduate thesis abstracts. On the contrary, in the Hard Science' undergraduate thesis abstracts, Move 2 - Purpose and Move 3 - Methodology were the most frequent move used by the students. However, Move 1 - Introduction was the least move used by the cross-department students in making the abstracts.

Regarding the steps, there was no significant difference between two fields of study. Step 2 - making topic generalization and Step 1 - arguing for topic significance in Move 1 were the most common Steps that appeared in the abstracts. However, Move 1 Step 3 defining the key term(s) was only used by the Humanities students. The difference occurred in Move 3 Step 1 describing participants/data sources because it had the same percentage in the Indonesian abstracts, while in English abstracts, the Hard Science students used it the most.

For future research, the results of this study can help the authors to explore another element of the undergraduate thesis abstracts, such as language features including tenses, voices, and other language aspects. Moreover, the future studies can also analyse the rhetorical move used not only by the Humanities and the Hard Science students, but also by other students from other field of study. In addition, not only in the undergraduate thesis abstracts, but this rhetorical analysis also can be conducted on other kind of academic writing, such as dissertations. Then, future studies can conclude whether the results that were found in this study can be used as the guidelines by students from different disciplines in making the undergraduate thesis abstracts or not. It is also recommended for the university parties to provide a template in making the abstracts, whether the undergraduate, the thesis, or the dissertation abstracts, in order for their students to create the good one. Then, by understanding the use of rhetorical move, including the use of move and its steps, hopefully the students can make a good abstract for their academic writings.

\section{ACKNOWLEDGMENTS}

This study was supported by a grant from the Research and Community Service Unit, Universitas Pendidikan Indonesia. The authors would like to express appreciation for all the support provided.

\section{REFERENCES}

Amnuai, W. (2019). Analyses of Rhetorical Moves and Linguistic Realizations in Accounting Research Article Abstracts Published in International and Thai-Based Journals. SAGE Open, 1-9. DOI: https://doi.org/10.1177/2158244018822384

Bhatia, V. K. (1993). Analysing Genre Language Use in Professional Settings. New York: Routledge.

Chandrasekhar, R. (2002). How to write a thesis: A working guide. The University of Western Australia. Retrieved from https://www.student.uwa.edu.au/_data/assets/pdf file/0007/1919239/How-to-write-a-thesis-Aworking-guide.pdf

Hogue, A. (2008). First Steps in Academic Writing, Second Edition. New York: Pearson Longman.

Hyland, K. (2000). Disciplinary Discourses: Social Interactions in Academic Writing. United States of America: The University of Michigan Press.

Kurniawan, E., Lubis, A. H., Suherdi, D., \& Danuwijaya, A. A. (2019). Rhetorical Organization of Applied Linguistics Abstracts: Does Scopus Journal Quartile Matter? Journal of Language Studies, 4, 184-202. DOI: http://doi.org/10.17576/gema-2019-1904-10

Li, X. (2020). Mediating Cross-Cultural Differences in Research Article Rhetorical Moves in Academic Translation: A Pilot Corpus-Based Study of Abstracts. Lingua, 238, 1-11. DOI: https://doi.org/10.1016/j.lingua.2020.102795

Litosseliti, L. (2010). Research Methods in Linguistics. New York: Continuum.

McCombes, S. (2019). How to write an Abstract. Retrieved from https://www.scribbr.com/dissertation/abstract/

Rising, L. A. (2014). Re: What is the difference between a dissertation, thesis, paper and a publication? [Web $\log$ comment] Retrieved from https://www.quora.com/What-is-the-differencebetween-a-dissertation-thesis-paper-and-apublication

Saboori, F., \& Hashemi, M. R. (2013). A CrossDisciplinary Move Analysis of Research Article Abstracts. International Journal of Language Learning and Applied Linguistics World 
(IJLLALW), 4(4), 483-496. Retrieved from https://profdoc.um.ac.ir/articles/a/1038627.pdf

Tamela, E. (2020). Move Structure Analysis on Research Article Abstracts in National and International SCOPUS Indexed Journals. International Conference on English Language Teaching (ICONELT 2019), 434I (pp. 12-17). Atlantis Press. DOI: https://doi.org/10.2991/assehr.k.200427.004

Turmudi, D. (2017). Rethinking Academic Essay Writing: Selected Genres. Premise: Journal of
English Education and Applied Linguistics, 6(2), 119-138. Retrieved from http://ojs.fkip.ummetro.ac.id/index.php/english/arti cle/view/1052/757

Wu, M. (2019). Research on Quality Improvement of the Undergraduate Thesis Based on TQM Concept. 5th International Conference on Humanities and Social Science Research (ICHSSR 2019), 319, (pp. 398402). Atlantis Press. DOI: https://doi.org/10.2991/ichssr-19.2019.76 